\title{
Fear of Childbirth and Associated Risk Factors in Healthy Pregnant Women in Northwest of China: A Cross-Sectional Study
}

\author{
Xiaolan Zhou ${ }^{1,2}$ \\ Hua Liu ${ }^{2}$ \\ Xiaohong $\mathrm{Li}^{2}$ \\ Shaoru Zhang' \\ 'School of Nursing, Xi'an Jiaotong \\ University, Xi'an, Shaanxi, People's \\ Republic of China; ${ }^{2}$ School of Nursing, \\ Xi'an Medical University, Xi'an, Shaanxi, \\ People's Republic of China
}

\begin{abstract}
Aim: Fear of childbirth (FOC) is an extreme state of anxiety, distress and worry about childbirth. Despite its common occurrence, the prevalence and risk factors for FOC are inadequately understood in the northwestern region of China.

Purpose: This study aimed to examine the prevalence and risk factors for fear of childbirth (FOC) in a cohort of pregnant women in northwest of China.
\end{abstract}

Patients and Methods: A total of 922 healthy pregnant women were included in this cross-sectional study. Participants filled out a questionnaire on socio-demographic characteristics, as well as the Childbirth Attitudes Questionnaire (CAQ), the Multidimensional Scale of Perceived Social Support (MSPSS), the Edinburgh Postnatal Depression Scale (EPDS), and the Pregnancy Pressure Scale (PPS). Psychosocial factors were analyzed to determine their association with fear of childbirth. Optimal scale regression analysis was used to determine the risk factors associated with FOC.

Results: The mean score on the CAQ was $33.92 \pm 10.17$. A total of $72 \%$ of participants reported low to mild FOC. Six percent $(n=51 / 922)$ and $22 \%(n=199 / 922)$ of pregnant women reported severe and moderate FOC, respectively. Based on optimal scaling regression analysis, the factors most strongly associated with FOC were residence, marital status, parity, gestational age, relationship with partner, pregnancy stress, social support and depressive symptoms.

Conclusion: This study indicates the high prevalence of FOC $(70.3 \%$, ranging from mild to severe) in healthy pregnant women in northwest of China. FOC showed a positive correlation with pregnancy-related stress and depressive symptoms and a negative correlation with social support. Screening for FOC and helping pregnant women identify a support system early in pregnancy could reduce a woman's stress level and severity of depression.

Keywords: fear of childbirth, depression, pregnancy stress, social support, pregnant women

\section{Introduction}

Pregnancy, birth and the transition to parenthood are common processes that hold significant social and emotional implications for the life of women and their families. ${ }^{1}$ Childbirth is a multidimensional, multivariant and unique experience for each pregnant woman. ${ }^{2}$ Although most childbirths are low-risk from a physiological point of view, most women have some degree of fear or anxiety about childbirth during their pregnancy. ${ }^{3}$ Fear of childbirth (FOC) is an extreme state of anxiety from phobia about childbirth. ${ }^{4}$ FOC in pregnant women revolves around concerns such as the well-being of the child, pain, loss of control, medical
Correspondence: Shaoru Zhang School of Nursing, Xi'an Jiaotong University, Xi'an, Shaanxi, People's Republic of China

Tel +86-18681865789

Fax +86-29-82657015

Email shaoru1958@I26.com 
interventions and the medical environment, unfamiliar healthcare providers during childbirth, and lack of support. $^{5-7}$ FOC is generally seen as an anxiety disorder or a phobia-like fear. ${ }^{8}$ Symptoms include physical complaints, nightmares, and difficulties in concentrating on work or family activities, as well as a strong desire for caesarean delivery. ${ }^{9}$

Reported incidence of FOC in pregnant women ranges from $8 \%$ in Europe to $24 \%$ in Australia, ${ }^{10} 25 \%$ in Asia, ${ }^{11}$ and $26.9 \%$ in the United States, ${ }^{12}$ with a recent systematic review reporting a global incidence of severe FOC of $6-10 \%{ }^{13}$ Severe FOC is associated with increased use of labour analgesia, elective caesarean section, poor delivery experience, and emotional imbalance (eg, post-traumatic stress symptoms). ${ }^{14}$ Previous studies have found several risk factors for FOC in pregnant women, including maternal age, low educational level, parity, gestational age, depression, lack of social support, low self-esteem and low childbirth self-efficacy. ${ }^{15-18}$ Symptoms of FOC, including maternal anxiety and emotional distress, have been linked to increased fetal heart rate and decreased fetal motility in utero. ${ }^{19}$

FOC has recently attracted the attention of academic researchers in China, where the prevalence of FOC during pregnancy has been reported at $79.2 \%(32.29 \pm 6.25),{ }^{20}$ and $73.1 \%(33.28 \pm 9.22){ }^{21}$ the incidence of severe FOC was reported at $4.4 \%$ in Anhui province. ${ }^{21}$ Although efforts have been taken to identify risk factors of FOC in China and to overcome its effects, prevalence as well as risk factors are currently rising in the country. ${ }^{22}$ Furthermore, few studies have investigated risk factors associated with FOC northwest of China.

Most research to date on FOC and its risk factors have been conducted in Scandinavian and other European countries. Compared with Chinese women, especially women in Shaanxi, participants in European studies differ in terms of living background, ethnicity and religion, as well as social structures. Findings from European studies on FOC may therefore not be generalizable to the Chinese population. To address these concerns, we investigated the prevalence and risk factors for FOC in a cohort of pregnant women in Shaanxi Province, which is located in northwestern China.

\section{Materials and Methods}

\section{Study Design}

We conducted a cross-sectional study of pregnant women receiving routine antenatal care. Study participants completed questionnaires on socio-demographic characteristics, FOC, and other psychological variables.

\section{Sample Size}

We calculated the minimum acceptable sample size (n) using the following Cochrane formula.

$$
n=\frac{Z^{2} P(1-P)}{d^{2}}
$$

$\mathrm{Z}=\mathrm{Z}$ statistics $=1.96$ for a $95 \%$ confidence interval $(\mathrm{CI})$;

$\mathrm{P}=$ prevalence of FOC $(73 \%)^{21}$ among third-trimester pregnant women;

$d=$ margin of error, which was considered to be $3 \%$ for this study.

The minimum sample size calculated was 896 cases. Considering that there might be a $10 \%$ non-response rate, the sample was expanded by $10 \%$, leading to a final sample size of 986 cases, and 1000 participants were recruited.

\section{Setting and Participants}

A nonprobability convenience sampling method was used to identify potential study participants. Xi'an is the provincial capital of Shaanxi Province and has a population of approximately 10 million. Participants were recruited from Northwest Women's and Children's Hospital, which is the largest regional maternal and children's hospital in Xi'an, with over 24,000 births per year.

\section{Participants}

We invited healthy pregnant women to participate in the study during a routine prenatal visit to the Northwest Women's and Children's Hospital between May and October 2019. We screened 1000 women who met the following inclusion criteria: (1) age $\geq 18$ years; (2) gestational age $\geq 14$ weeks and $<41$ weeks; and (3) intrauterine pregnancy with a single fetus. Exclusion criteria were as follows: (1) unable to read Chinese, (2) history of mental abnormality, and (3) preeclampsia, hemorrhage, severe organic diseases, or mental illness. Consent was obtained from each of the eligible women before they completed the questionnaires. Sixty-two women declined to participate in the study.

\section{Study Procedure and Data Collection}

Participants were asked to fill out the sociodemographic characteristics questionnaire as well as four other study questionnaires (described below). A researcher or midwife was present to explain the study to the study participants and answer questions. Questionnaires were distributed and 
collected by the investigator onsite and each questionnaire took about 25 minutes for the participant to complete. Participants with missing data for age $(n=3)$, education $(\mathrm{n}=2)$, occupation $(\mathrm{n}=3)$, marital status $(\mathrm{n}=1)$, relationship with mother-in-law $(n=3)$ or parity $(n=4)$ were excluded, leaving an analytical sample of 922 women.

\section{Instruments}

Sociodemographic Characteristics Questionnaire

The sociodemographic characteristics questionnaire was developed based on a literature review and included 24 items relating to women's age, educational level, occupation, monthly household income, area of residence, marital status, housing satisfaction, relationship with partner, relationship with mother-in-law, and gestational age at time of questionnaire completion.

\section{Childbirth Attitudes Questionnaire (CAQ)}

The Childbirth Attitudes Questionnaire $(\mathrm{CAQ})^{23,24}$ is an instrument adapted from Harman ${ }^{25}$ and Areskog et al $^{7}$ to measure FOC. The questionnaire includes 16 items rated on a Likert scale $(1=$ never; $4=$ severe $)$ and covering 4 dimensions (baby-related, pain and injury-related, general and personal control-related, and medical interventions and hospital care-related fears), with total scores ranging from 16 to 64 points. Higher total scores indicate more severe FOC, which is classified into four levels based on the total score: low (score 16-27), mild (28-39), moderate (40-51), and severe $(52-64) .{ }^{26}$ The original CAQ has good reliability and validity. ${ }^{23}$ The Chinese version of the $C A Q$ has been validated in pregnant women in China and has been found to have an internal consistency rating of $0.91{ }^{26}$ We used the Chinese version of the CAQ for this study, which yielded a Cronbach's alpha of 0.93 .

\section{Pregnancy Pressure Scale (PPS)}

Antenatal stress was measured using the Pregnancy Pressure Scale (PPS). This instrument was originally developed by Chen et $\mathrm{al}^{27}$ in Taiwan and is a self-report measurement that includes 30 items rated on a 4-point scale $(0=$ not at all, $3=$ severe). The PPS was designed to reflect a Chinese cultural framework. The measure assesses stress in relation to the health and safety of the mother and child, recognition of parental roles, and changes in body shape and physical activity. Higher scores indicate higher levels of pregnancy stress. The PPS has shown acceptable reliability in Chinese women. ${ }^{28}$ The Cronbach's alpha internal consistency rating of the PPS in this study was 0.94 .

\section{Multidimensional Scale of Perceived Social Support (MSPSS)}

Perceived social support was measured using the Multidimensional Scale of Perceived Social Support (MSPSS), developed by Zimet et al. ${ }^{29}$ This instrument includes 12 questions assessing perceived social support across three dimensions (support from family, friends, and significant others). Participants indicate their level of agreement or disagreement with each item using a sevenpoint Likert scale, with responses ranging from 1 (completely disagree) to 7 (strongly agree). Each of the three dimensions has four items and individual domain scores vary from 4 to 28 , with higher scores corresponding to higher levels of perceived social support. We used the Chinese version of the MSPSS, ${ }^{30}$ which showed a Cronbach's alpha rating of 0.93 in our study.

\section{Edinburgh Postnatal Depression Scale (EPDS)}

Antenatal depressive symptoms were measured with the Edinburgh Postnatal Depression Scale (EPDS), originally developed by Cox et al. ${ }^{31}$ This instrument is the most widely used screening questionnaire for postpartum depression and is also acceptable for use in screening for antenatal depressive symptoms. ${ }^{32}$ The EPDS is a 10 -item self-report questionnaire, with item scores ranging from 0 to 3. The Chinese version of EPDS is widely used among Chinese women during pregnancy ${ }^{33}$ and shows good reliability and validity. The Cronbach's alpha rating of the EPDS in this study was 0.85 .

\section{Ethical Considerations}

The study was approved by the Ethics Committee of Xi'an Medical University. All study participants were informed about the aim of the study and were assured that information collected would be used only for research purposes. All women enrolled in this study provided informed consent before participation. This study was conducted in accordance with the Declaration of Helsinki.

\section{Statistical Analysis}

Statistical analyses were conducted using SPSS software version 24.0. Descriptive statistics, including frequency counts, percentages, means and standard deviations, were used to summarize demographic, obstetric and psychological variables. Potentially significant predictors of FOC were identified using one-sided independent sample $t$-tests, analysis of variance, and Pearson product-moment correlations for dichotomous, categorical, and continuous variables 
respectively. Optimal scaling (CATREG) regression was then used to measure associations between potential predictors and FOC. Gestational age, social support, pregnancy stress, and EPDS were analyzed as continuous variables; relationship with partner $($ close $=0$; good $=1$; moderate $=$ 2 ; occasional conflicts $=3$ ) and residence (rural area $=0$; town $/$ county $=1$; city $=2$ ) were considered as nominal variables; parity (nulliparae $=0$; multiparae $=1$ ) and marital status were dichotomized. A p-value of $<0.05$ was considered statistically significant.

\section{Results}

\section{Sample Characteristics}

Among 1000 eligible women approached for participation, 62 women declined to participate and 16 women provided informed consent but did not complete the questionnaires, leaving an analytic sample of 922 women. Sociodemographic and obstetric characteristics of the sample are shown in Table 1. Participants included 567 nulliparous women and 355 multiparous women, with participant ages ranging from 18 to 45 years (mean $=28.13$ years, $\mathrm{SD}=4.09$ ). The mean gestational age at enrolment was 36.18 weeks $(\mathrm{SD}=5.24)$.

\section{Fear of Childbirth (FOC)}

The mean score on the CAQ was 33.92 (SD $=10.17$, range $16-64)$, and the majority of participants scored at least $28(\mathrm{n}=$ $648,70.3 \%$ ). Table 2 shows FOC levels in relation to sociodemographic and other characteristics that were significantly associated with FOC. Thirty-one percent $(n=174 / 567)$ of nulliparous women and $21 \%(\mathrm{n}=76 / 355)$ of multiparous women had moderate to severe fear levels. It was found that younger women tended to report higher levels of FOC, as did women with a high school or technical school education. FOC was also elevated among farmers, residents of towns or counties, women reporting a low degree of housing satisfaction, and those reporting a poor relationship with their mother-in-law. Finally, lower levels of social support, higher levels of pregnancy pressure, and elevated depressive symptoms were associated with higher FOC scores.

\section{Pregnancy Pressure, Perceived Social Support, and Depressive Symptoms}

Women with mild pregnancy stress had a mean score of 30.81 for FOC, and $15.2 \%(99 / 651)$ of participants in this sub-group reported moderate or severe FOC. Among women with severe pregnancy stress levels, mean FOC score was $49.91(\mathrm{SD}=14.48)$, while $63.6 \%(7 / 11)$ of these participants reported moderate or severe FOC (Table 2).

Of women reporting a high level of social support, the mean FOC score was 33.37, and one fourth of these participants (199/797) reported moderate or severe FOC. Among participants reporting low levels of social support, the mean FOC score was 45.50, and three of the four women reported moderate or severe FOC (Table 2).

Slightly more than one fourth of participants $(27.0 \%$, 249/922) scored $\geq 13$ on the EPDS. Slightly over half of participants $(52.1 \%, 480 / 922)$ scored $\leq 9$ on the EDPS, and $15.4 \%$ of these women reported moderate or severe FOC.

Mean scores of each item in the CAQ are shown in Table 3. The overall mean score of all questionnaire items was $2.12(\mathrm{SD}=0.636)$. The most commonly reported fears on the CAQ were having to undergo a caesarean section and fear of the baby being injured during childbirth, whereas the least commonly reported fears were nightmares about childbirth and fear of the hospital environment.

\section{Fear of Childbirth in Relation to Socio-Demographic and Obstetric Characteristics}

Pregnancy stress, social support, depressive symptoms, and parity were significantly correlated with scores on the CAQ (Table 4). Higher levels of perceived stress, lack of social support, and depressive symptoms were associated with higher levels of FOC, whereas multiparity was associated with lower levels of FOC.

\section{Predictors of Fear or Childbirth in Adjusted Analyses}

Optimal scaling regression allows various types of categorical variables to be included as independent variables. In this analysis, nonlinear transformations were used to transform original categorical variables, and then iteration was repeated in order to find an optimal equation. In our analysis, CAQ score was the dependent variable while sociodemographic and psychosocial characteristics were independent variables. The best-fit regression model revealed eight variables that explained $38 \%$ of the variance in CAQ scores. Maternal characteristics predicting FOC in the adjusted regression analysis included place of residence, marital status, parity, gestational age, relationship with partner, pregnancy stress, social support and depressive symptoms (Table 5). Other socioeconomic 
Table I Socio-Demographic and Obstetric Characteristics of Study Participants ( $N=922)$

\begin{tabular}{|c|c|c|c|}
\hline Maternal Characteristics & n (\%) & Maternal Characteristics & n (\%) \\
\hline Ethnic group & & Support of husband for pregnancy & \\
\hline Han & $895(97.1)$ & Very supportive & $848(92.0)$ \\
\hline Other & $27(2.9)$ & Unsupportive & $74(8.0)$ \\
\hline Age & & Relationship with partner & \\
\hline$\leq 25$ & $222(24.1)$ & Close & $47 \mid(5 I .1)$ \\
\hline $26-30$ & $478(51.8)$ & Good & $391(42.4)$ \\
\hline $31-35$ & $179(19.4)$ & General & $25(2.7)$ \\
\hline$\geq 36$ & $43(4.7)$ & Occasional conflicts & $35(3.8)$ \\
\hline Education level & & Relationship with mother-in-law & \\
\hline Middle school and below & $197(21.4)$ & Good & $709(76.9)$ \\
\hline High school/Vocational school & $249(27.0)$ & Fair & $201(21.8)$ \\
\hline University or above & $476(51.6)$ & Poor & $12(1.3)$ \\
\hline Occupation & & Parity & \\
\hline Civil servant/Employee of institutions & $123(13.3)$ & Nullipara & $567(6 \mid .5)$ \\
\hline Employee of enterprises & $257(27.9)$ & Multipara & $355(38.5)$ \\
\hline Farmer & $160(17.4)$ & Gestational age & \\
\hline Freelancer & $382(4 \mid .4)$ & $<28 w$ & $67(7.3)$ \\
\hline Residence & & $28-36 w$ & $244(26.4)$ \\
\hline Rural area & $370(40.1)$ & $\geq 37 w$ & $611(66.3)$ \\
\hline Town/County & $174(18.9)$ & Preferred route of delivery & \\
\hline City & $378(4 I .0)$ & Vaginal delivery & $75 I(81.5)$ \\
\hline Marital status & & Caesarean delivery & $|7|(\mid 8.5)$ \\
\hline Married & 891 (96.6) & Social support & \\
\hline Unmarried & $31(3.4)$ & Lower (12-36) & $4(0.4)$ \\
\hline Monthly household income & & Middle (37-60) & $121(13.1)$ \\
\hline$<¥ 2000$ & $110(11.9)$ & Higher (6I-84) & $797(86.5)$ \\
\hline$¥ 2000-4500$ & $594(64.4)$ & Pregnancy stress & \\
\hline$>¥ 4500$ & $218(23.7)$ & Mild (0-35) & $65 I(70.6)$ \\
\hline Route prenatal care & & Moderate (36-72) & $260(28.2)$ \\
\hline Yes & $789(85.57)$ & Severe $(>72)$ & II (I.2) \\
\hline No & $133(14.43)$ & EPDS score & \\
\hline Housing satisfaction & & $\leq 9$ & $480(52.1)$ \\
\hline Satisfactory & $212(23.0)$ & $10-12$ & $193(20.9)$ \\
\hline Fair & $657(7 \mid .3)$ & $\geq 13$ & $249(27.0)$ \\
\hline Not satisfied & $53(5.7)$ & & \\
\hline
\end{tabular}

characteristics, including age, education, occupation, household income, and housing satisfaction, were not significantly associated with FOC in the adjusted analyses.

\section{Discussion}

We measured the prevalence and risk factors for FOC in a sample of pregnant women in northwestern China using a cross-sectional study design. Meeting maternal mental health needs is an important priority for maternal and child healthcare providers; however, China has paid special attention to maternal mortality, infant mortality and other physical health problems while neglecting mental health problems. ${ }^{34}$ Identification of severe FOC early in pregnancy will allow healthcare professionals to provide appropriate interventions to support and guide pregnant women and nurture their psychological health throughout pregnancy. Several systematic reviews and meta-analyses revealed that interventions including prenatal education 
Table 2 Maternal Characteristics by Level of Fear of Childbirth $(N=922)$

\begin{tabular}{|c|c|c|c|c|c|c|}
\hline \multirow[t]{2}{*}{ Maternal Characteristics } & \multirow{2}{*}{$\begin{array}{l}\text { CAQ Score } \\
\text { Mean (SD) }\end{array}$} & \multicolumn{4}{|c|}{ Level of Fear of Childbirth } & \multirow[t]{2}{*}{$\boldsymbol{F}$} \\
\hline & & $\begin{array}{l}\text { Low } n=274 \\
\text { No (\%) }\end{array}$ & $\begin{array}{l}\text { Mild } n=398 \\
\text { No (\%) }\end{array}$ & $\begin{array}{l}\text { Moderate n = } 199 \\
\text { No (\%) }\end{array}$ & $\begin{array}{l}\text { Severe } n=51 \\
\text { No (\%) }\end{array}$ & \\
\hline $\begin{array}{l}\text { Age } \\
\begin{array}{l}\leq 25 \text { years } \\
26-30 \text { years } \\
3 \mathrm{I}-35 \text { years } \\
\geq 36 \text { years }\end{array}\end{array}$ & $\begin{array}{l}35.41(10.75) \\
33.96(10.05) \\
32.62(9.97) \\
31.18(8.16)\end{array}$ & $\begin{array}{l}56(20.5) \\
134(48.9) \\
70(25.5) \\
14(5.1)\end{array}$ & $\begin{array}{l}95(23.9) \\
212(53.3) \\
67(16.8) \\
24(6.0)\end{array}$ & $\begin{array}{l}54(27.1) \\
106(53.3) \\
35(17.6) \\
4(2.0)\end{array}$ & $\begin{array}{l}17(33.3) \\
26(51.0) \\
7(13.7) \\
I(2.0)\end{array}$ & $3.629 *$ \\
\hline $\begin{array}{l}\text { Education level } \\
\text { Middle school and below } \\
\text { High school/technical } \\
\text { school } \\
\text { University or above }\end{array}$ & $\begin{array}{l}34.70(11.02) \\
35.09(10.69) \\
32.98(9.44)\end{array}$ & $\begin{array}{l}57(20.8) \\
65(23.7) \\
152(55.5)\end{array}$ & $\begin{array}{l}80(20.1) \\
108(27.1) \\
210(52.8)\end{array}$ & $\begin{array}{l}47(23.7) \\
55(27.6) \\
97(48.7)\end{array}$ & $\begin{array}{l}\text { I3 (25.5) } \\
21(41.2) \\
17(33.3)\end{array}$ & $4.270^{*}$ \\
\hline $\begin{array}{l}\text { Occupation } \\
\text { Civil servant/Employee of } \\
\text { institutions } \\
\text { Employee of enterprises } \\
\text { Farmer } \\
\text { Freelancer }\end{array}$ & $\begin{array}{l}32.68(10.13) \\
32.76(9.08) \\
34.86(10.57) \\
34.70(10.18)\end{array}$ & $\begin{array}{l}44(16.1) \\
87(31.8) \\
46(16.7) \\
97(35.4)\end{array}$ & $\begin{array}{l}49(12.3) \\
111(27.9) \\
62(15.6) \\
176(44.2)\end{array}$ & $\begin{array}{l}25(12.6) \\
48(24.1) \\
42(21.1) \\
84(42.2)\end{array}$ & $\begin{array}{l}5(9.8) \\
11(21.6) \\
10(19.6) \\
25(49.0)\end{array}$ & $2.933^{*}$ \\
\hline $\begin{array}{l}\text { Residence } \\
\text { Rural area } \\
\text { Town/County } \\
\text { City }\end{array}$ & $\begin{array}{l}33.92(10.21) \\
36.22(9.93) \\
32.87(10.11)\end{array}$ & $\begin{array}{l}107(39.1) \\
31(11.3) \\
136(49.6)\end{array}$ & $\begin{array}{l}167(42.0) \\
88(22.1) \\
143(35.9)\end{array}$ & $\begin{array}{l}75(37.7) \\
43(21.6) \\
81(40.7)\end{array}$ & $\begin{array}{l}21(41.2) \\
12(23.5) \\
18(35.3)\end{array}$ & $6.570 * *$ \\
\hline $\begin{array}{l}\text { Housing satisfaction } \\
\text { Satisfactory } \\
\text { Neutral } \\
\text { Not satisfied }\end{array}$ & $\begin{array}{l}32.43(9.65) \\
33.96(10.14) \\
39.35(10.95)\end{array}$ & $\begin{array}{l}76(27.7) \\
|9|(69.7) \\
7(2.6)\end{array}$ & $\begin{array}{l}91(22.9) \\
286(71.9) \\
21(5.2)\end{array}$ & $\begin{array}{l}35(17.6) \\
145(72.9) \\
19(9.5)\end{array}$ & $\begin{array}{l}10(19.6) \\
35(68.6) \\
6(11.8)\end{array}$ & $5.444 * *$ \\
\hline $\begin{array}{l}\text { Relationship with mother-in- } \\
\text { law } \\
\text { Good } \\
\text { Fair } \\
\text { Poor }\end{array}$ & $\begin{array}{l}33.20(9.88) \\
36.11(10.42) \\
39.50(15.79)\end{array}$ & $\begin{array}{l}232(84.7) \\
39(14.2) \\
3(1.1)\end{array}$ & $\begin{array}{l}292(73.4) \\
102(25.6) \\
4(1.0)\end{array}$ & $\begin{array}{l}155(77.9) \\
42(21.1) \\
2(1.0)\end{array}$ & $\begin{array}{l}30(58.8) \\
18(35.3) \\
3(5.9)\end{array}$ & $8.361^{* *}$ \\
\hline $\begin{array}{l}\text { Parity } \\
\text { Nullipara } \\
\text { Multipara }\end{array}$ & $\begin{array}{l}35.01(10.43) \\
32.18(9.50)\end{array}$ & $\begin{array}{l}\text { I50 (54.7) } \\
\text { I24(45.3) }\end{array}$ & $\begin{array}{l}243(6 \mathrm{I} .1) \\
155(38.9)\end{array}$ & $\begin{array}{l}133(66.8) \\
66(33.2)\end{array}$ & $\begin{array}{l}41(80.4) \\
10(19.6)\end{array}$ & $|7.07|$ ** \\
\hline $\begin{array}{l}\text { Gestational age } \\
<28 w \\
28-36 w \\
>36 w\end{array}$ & $\begin{array}{l}32.49(8.92) \\
32.77(9.62) \\
34.53(10.47)\end{array}$ & $\begin{array}{l}23(8.4) \\
72(26.3) \\
179(65.3)\end{array}$ & $\begin{array}{l}29(7.3) \\
126(3 \mid .7) \\
243(6 \mid .0)\end{array}$ & $\begin{array}{l}14(7.0) \\
34(17.1) \\
151(75.9)\end{array}$ & $\begin{array}{l}\text { I }(2.0) \\
12(23.5) \\
38(74.5)\end{array}$ & $3.321 *$ \\
\hline $\begin{array}{l}\text { Route prenatal care } \\
\text { Yes } \\
\text { No }\end{array}$ & $\begin{array}{l}33.55(9.83) \\
36.08(11.85)\end{array}$ & $\begin{array}{l}237(86.5) \\
37(13.5)\end{array}$ & $\begin{array}{l}346(86.9) \\
52(13.1)\end{array}$ & $\begin{array}{l}170(85.4) \\
29(14.6)\end{array}$ & $\begin{array}{l}36(70.6) \\
15(29.4)\end{array}$ & $7.060 * *$ \\
\hline $\begin{array}{l}\text { Social support } \\
\text { High }(6 \mathrm{I}-84) \\
\text { Moderate }(37-60) \\
\text { Low }(12-36)\end{array}$ & $\begin{array}{l}33.37(9.95) \\
37.13(10.63) \\
45.50(17.38)\end{array}$ & $\begin{array}{l}250(9 \mid .2) \\
23(8.4) \\
I(0.4)\end{array}$ & $\begin{array}{l}348(87.4) \\
50(12.6) \\
0(0.0)\end{array}$ & $\begin{array}{l}160(80.4) \\
38(19.1) \\
I(0.5)\end{array}$ & $\begin{array}{l}39(76.5) \\
10(19.6) \\
2(3.9)\end{array}$ & $9.950 * *$ \\
\hline
\end{tabular}

(Continued) 
Table 2 (Continued).

\begin{tabular}{|c|c|c|c|c|c|c|}
\hline \multirow[t]{2}{*}{ Maternal Characteristics } & \multirow{2}{*}{$\begin{array}{l}\text { CAQ Score } \\
\text { Mean (SD) }\end{array}$} & \multicolumn{4}{|c|}{ Level of Fear of Childbirth } & \multirow[t]{2}{*}{$\boldsymbol{F}$} \\
\hline & & $\begin{array}{l}\text { Low } n=274 \\
\text { No (\%) }\end{array}$ & $\begin{array}{l}\text { Mild n = } 398 \\
\text { No (\%) }\end{array}$ & $\begin{array}{l}\text { Moderate } n=199 \\
\text { No }(\%)\end{array}$ & $\begin{array}{l}\text { Severe } \mathbf{n}=\mathbf{5} \text { I } \\
\text { No (\%) }\end{array}$ & \\
\hline Pregnancy Stress & & & & & & $123.882 * *$ \\
\hline Mild & $30.81(8.58)$ & $250(91.2)$ & $302(75.9)$ & $85(42.7)$ & $14(27.5)$ & \\
\hline Moderate & $41.02(9.45)$ & $23(8.4)$ & $93(23.4)$ & II 4 (57.3) & $30(58.8)$ & \\
\hline Severe & $49.91(14.48)$ & I $(0.4)$ & $3(0.7)$ & $0(0.0)$ & $7(13.7)$ & \\
\hline EPDS score & & & & & & $71.174 * *$ \\
\hline$\leq 9$ & $30.69(9.09)$ & $196(7 \mid .5)$ & $210(52.8)$ & $60(30.2)$ & $14(27.5)$ & \\
\hline $10-12$ & $34.80(9.54)$ & $44(16.1)$ & $94(23.6)$ & $45(22.6)$ & $10(19.6)$ & \\
\hline$\geq 13$ & $39.46(10.15)$ & $34(12.4)$ & $94(23.6)$ & $94(47.2)$ & $27(52.9)$ & \\
\hline
\end{tabular}

Notes: $* p<0.05 . * * p<0.01$.

Table 3 Childbirth Attitude Questionnaire Item Scores $(N=922)$

\begin{tabular}{|c|c|c|c|}
\hline $\begin{array}{l}\text { Original } \\
\text { Item No. }\end{array}$ & CAQ Item & Mean & SD \\
\hline 9 & I have fear of having to have a caesarean section. & 2.49 & 1.031 \\
\hline $\mathrm{II}$ & I have fear of the baby being injured during the childbirth. & 2.49 & 0.956 \\
\hline 2 & I am really afraid of giving birth. & 2.39 & 0.932 \\
\hline 6 & I have some fear of something being wrong with the baby. & 2.38 & 0.951 \\
\hline 10 & I have fear of being torn with the birth of the baby. & 2.25 & 0.944 \\
\hline 12 & I have fear of painful labor contractions. & 2.19 & 0.937 \\
\hline 5 & I have fear I will not be able to help during the childbirth. & 2.18 & 0.907 \\
\hline 8 & I have fear of being left alone during labor. & 2.16 & 0.971 \\
\hline 16 & $\begin{array}{l}\text { Overall, I would rate my anxiety about childbirth as I (no anxiety), } 2 \text { (low anxiety), } 3 \\
\text { (moderate anxiety), } 4 \text { (high anxiety). }\end{array}$ & 2.1 & 0.828 \\
\hline 13 & I have difficulty relaxing when thinking of the coming birth. & 2.08 & 0.891 \\
\hline 4 & I have fear of bleeding too much during the childbirth. & 2.04 & 0.922 \\
\hline 1 & I have fear of losing control of myself at the childbirth. & 2.01 & 0.830 \\
\hline 7 & I have fear of painful injections. & 1.98 & 0.925 \\
\hline 15 & I have fear of not getting the kind of care that I want. & 1.85 & 0.850 \\
\hline 14 & I have fear of the hospital environment. & 1.74 & 0.836 \\
\hline 3 & I have nightmares about the childbirth. & 1.6 & 0.863 \\
\hline \multicolumn{2}{|c|}{ Total Childbirth Attitude Questionnaire score } & 33.92 & 10.17 \\
\hline
\end{tabular}

and counseling can reduce women's FOC $;^{35-37}$ thereby reducing the risk for future negative consequences to both psychological and obstetric health.
In this study, $27 \%$ of the 922 women expressed severe or moderate FOC. This is similar to the prevalence found in a previous study by Areskog et al. ${ }^{7}$ The mean total CAQ 
Table 4 Variables Correlated with Scores on the Childbirth Attitude Questionnaire $(N=922)$

\begin{tabular}{|l|l|l|}
\hline Variables & $\boldsymbol{R}$ & $\boldsymbol{P}$-value \\
\hline Pregnancy stress & 0.598 & 0.000 \\
Stress from seeking identifying maternal role & 0.395 & 0.000 \\
Stress from seeking safe passage for herself and her child & 0.600 & 0.000 \\
Stress from altering body structure and body function & 0.503 & 0.000 \\
\hline Social support & -0.246 & 0.000 \\
From family & -0.232 & 0.000 \\
From friends & -0.240 & 0.000 \\
From significant others & -0.193 & 0.000 \\
\hline EPDS score & 0.434 & 0.000 \\
Anhedonia & 0.328 & 0.000 \\
Anxiety & 0.379 & 0.000 \\
Depression & 0.373 & 0.000 \\
Parity & -0.135 & 0.000 \\
\hline
\end{tabular}

Table 5 Results from Linear Regression Analyses Predicting CAQ Scores

\begin{tabular}{|l|l|l|l|l|}
\hline Variables & $\boldsymbol{\beta}$ & $\boldsymbol{S E}$ & $\boldsymbol{F}$ & $\boldsymbol{P}$-value \\
\hline Residence & -0.088 & 0.034 & 6.495 & 0.002 \\
Marital status & -0.058 & 0.022 & 6.703 & 0.000 \\
Parity & 0.097 & 0.030 & 10.448 & 0.001 \\
Gestational age & 0.080 & 0.027 & 8.855 & 0.003 \\
Relationship with partner & -0.059 & 0.032 & 3.453 & 0.032 \\
Pregnancy stress & 0.394 & 0.037 & 112.849 & 0.000 \\
Social support & -0.091 & 0.046 & 3.955 & 0.019 \\
Depressive symptoms & 0.220 & 0.036 & 37.788 & 0.000 \\
\hline
\end{tabular}

score in our study was 33.9 , with an overall mean item score of 2.1. These scores were slightly higher than most previous studies conducted in China and other countries. Previous studies from $\mathrm{China}^{38}$ reported mean total CAQ scores of $31.20(n=353)$ and $31.44(n=285)$ and mean overall item scores of 2.00 . Lowe ${ }^{17}$ reported a mean total CAQ score of 31.17 in a sample of pregnant women in the US. Finally, a study from Thailand reported an overall mean item score of $2.39,{ }^{18}$ slightly higher than the figure found in our study.

Further investigation of the individual CAQ items revealed that women in our study expressed the greatest level of concern over possible caesarean delivery. Based on this finding and those from a previous study, ${ }^{39}$ we believe that caesarean delivery was the concern of most pregnant women.

In this study, $86.4 \%$ of women reported sufficient social support (MSPSS score 61-84) during their current pregnancy, and social support was negatively associated with
FOC. Social support, including support from family, friends and significant others, is vital during significant events such as pregnancy, and it can reduce FOC by enhancing women's well-being and reducing stress levels. ${ }^{5,40}$ Social support provides a buffer in stressful environments. ${ }^{41}$ Without adequate emotional and social support, women are more likely to experience adverse pregnancy outcomes including preterm labor and perinatal depression. ${ }^{40,42}$

Numerous studies have shown that support from partners, family members and close friends can help pregnant women gain knowledge, increase self-confidence, and reduce stress and FOC. ${ }^{40,42}$ Spouses are the main source of social support that women tend to value most. ${ }^{43}$ Previous research has shown a significant relationship between lack of social support and FOC. ${ }^{44}$ Similarly, it was found in this study that lower levels of social support significantly predicted fear of birth $(\beta=0.091, p=0.019)$.

Slightly less than $30 \%$ of women in our study reported high levels of depressive symptoms (EPDS score $\geq 13$ ), 
and prenatal depressive symptoms were significantly associated with FOC. Eberhard-Gran et $\mathrm{al}^{45}$ found that depression during pregnancy was the strongest predictor of FOC. Another study found that women reporting high levels of depressive symptoms during pregnancy were more than twice as likely to experience fear of birth as those who reported low levels of depressive symptoms. ${ }^{46}$

In China, hospitalization for childbirth is advocated, and hospitals are considered as suitable and safe places for childbirth. The institutional delivery rate has been reported at 99.7\% in China overall and 99.9\% in Shaanxi Province. ${ }^{47}$ Urban areas, especially metropolises, have rich maternal and child healthcare resources. In contrast, rural area health service institutions for women and children still lack professional personnel and standardization. ${ }^{48}$ Pregnant women living in urban areas have access to better medical care, more convenient transportation and timely medical treatment than those living in rural areas. These factors are likely tied to reduced levels of FOC in populations located in urban areas.

Gestational age was significantly associated with FOC in our study ( $\beta=0.80, p=.003)$. This finding may be related to changes in stress across pregnancy. Pregnant women in the third trimester tend to be more concerned about their ability to handle childbirth and thus experience FOC. According to reports, $16 \%$ of pregnant women regard the last month of pregnancy as the period with the most severe psychological distress. ${ }^{49}$ Symptoms of anxiety and fear tend to increase in late pregnancy, especially when the woman is expecting her first child. ${ }^{50}$

This study included a larger proportion of nulliparous women than multiparous women $(61.5 \%$ vs $38.5 \%$ ), and nulliparous women were more likely to have FOC $(\mathrm{r}=-0.135, \mathrm{p}<0.01)$. This finding is congruent with findings from other countries. ${ }^{51}$ First-time mothers may not know what to expect during childbirth and so may experience higher levels of FOC than multiparous women, who may conversely have greater knowledge of childbirth. ${ }^{52}$ Primiparas may fear negative or horror stories about childbirth and may be more concerned about the delivery modes, childbirth pain, access to good postpartum care, and postpartum recovery in the face of an adverse event. ${ }^{6}$ However, a Finnish study found in contrast that the prevalence of FOC in multiparas was 1.9 times higher than that in primiparas. ${ }^{16}$ This result may be related to previous experiences of dystocia, operative vaginal delivery, pregnancy complications and other unfavourable delivery experiences. ${ }^{53}$

\section{Conclusion}

The results from this study indicate a high prevalence of FOC in healthy pregnant women in northwest of China. FOC showed a positive correlation with pregnancy-related stress and depressive symptoms and a negative correlation with social support. Findings from this study can support future research on FOC in China, including possible development of a screening questionnaire for FOC or psychoeducational interventions to reduce FOC. Additionally, the authors recommend future research focusing on the identification of strategies that will lead to a more positive childbirth experience for Chinese women and strategies for reducing the incidence of adverse obstetric outcomes.

\section{Strengths and Limitations}

Our study included a robust sample size, and we were thus able to detect significant associations between several factors and FOC. While all participants were seen at one hospital of Shaanxi Province, they came from a broad range of residential areas, as Northwest Women's and Children's Hospital is one of the largest women's and children's hospitals in northwestern China, with over 24,000 deliveries per year. Most pregnant women in the hospital's catchment area would indicate this institution as their first choice to obtain optimal maternal and childbirth healthcare with advanced examinations, diagnostics, and other services. Thus, the study population exhibited a substantial level of socioeconomic diversity. However, this study was conducted in a single health care center in northwestern China and participants were all in the second or third trimester of pregnancy; thus, our results may not be fully generalizable to other parts of China, especially the well-developed and "firsttier" cities, and to women at the beginning of pregnancy or those planning to become pregnant.

\section{Abbreviations}

FOC, fear of childbirth; EPDS, Edinburgh Postnatal Depression Scale; CAQ, childbirth attitudes questionnaire; $\mathrm{SD}$, standard deviation.

\section{Acknowledgments}

We are extremely grateful to all women who participated in the study; to members of the study group (Sun Y, Bai RF, and Yang CR) who contributed to the design of study instruments and/or interpretation of data presented in the paper; to Zhang TB and Cao GF, who contributed to the development of the 
study protocol; and to members of the study research team, who contributed to data collection and coding (Zhao ZL). We thank LetPub (www.letpub.com) for linguistic assistance and scientific consultation during the preparation of this manuscript.

\section{Disclosure}

The authors report no conflicts of interest in this work.

\section{References}

1. Fenwick J, Gamble J, Nathan E, Bayes S, Hauck Y. Pre- and postpartum levels of childbirth fear and the relationship to birth outcomes in a cohort of Australian women. J Clin Nurs. 2009;18(5):667-677. doi:10.1111/j.1365-2702.2008.02568.x

2. Larkin P, Begley CM, Devane D. Women's experiences of labour and birth: an evolutionary concept analysis. Midwifery. 2009;25(2):e49e59. doi:10.1016/j.midw.2007.07.010

3. Nilsson C, Lundgren I. Women's lived experience of fear of childbirth. Midwifery. 2009;25(2):e1-e9. doi:10.1016/j.midw.2007.01.017

4. Salomonsson B, Gullberg MT, Alehagen S, Wijma K. Self-efficacy beliefs and fear of childbirth in nulliparous women. J Psychosom Obstet Gynecol. 2013;34(3):116-121. doi:10.3109/ 0167482X.2013.824418

5. Fenwick J, Toohill J, Creedy DK, Smith J, Gamble J. Sources, responses and moderators of childbirth fear in Australian women: a qualitative investigation. Midwifery. 2015;31(1):239-246. doi:10.1016/j.midw.2014.09.003

6. Fisher C, Hauck Y, Fenwick J. How social context impacts on women's fears of childbirth: a Western Australian example. Soc Sci Med. 2006;63(1):64-75. doi:10.1016/j.socscimed.2005.11.065

7. Areskog B, Kjessler B, Uddenberg N. Identification of women with significant fear of childbirth during late pregnancy. Gynecol Obstet Invest. 1982;13(2):98-107. doi:10.1159/000299490

8. Zar M, Wijma K, Wijma B. Relations between anxiety disorders and fear of childbirth during late pregnancy. Clin Psychol Psychother. 2002;9(2):122-130. doi:10.1002/cpp.305

9. Saisto T, Halmesmäki E. Fear of childbirth: a neglected dilemma. Acta Obstet Gynecol Scand. 2003;82(3):201-208. doi:10.1034/ j.1600-0412.2003.00114.x

10. Toohill J, Creedy DK, Gamble J, Fenwick J. A cross-sectional study to determine utility of childbirth fear screening in maternity practice an Australian perspective. Women Birth. 2015;28(4):310-316. doi:10.1016/j.wombi.2015.05.002

11. Hanna-Leena Melender R. Experiences of fears associated with pregnancy and childbirth: a Study of 329 pregnant women. Birth. 2002;29 (2):101-111. doi:10.1046/j.1523-536X.2002.00170.x

12. Stoll K, Edmonds JK, Hall WA. Fear of childbirth and preference for cesarean delivery among young American women before childbirth: a Survey Study. Birth. 2015;42(3):270-276. doi:10.1111/birt.12178

13. O'Connell MA, Leahy-Warren P, Khashan AS, Kenny LC, O'Neill SM. Worldwide prevalence of tocophobia in pregnant women: systematic review and meta-analysis. Acta Obstet Gynecol Scand. 2017;96(8):907-920. doi:10.1111/aogs.13138

14. Söderquist J, Wijma B, Thorbert G, Wijma K. Risk factors in pregnancy for post-traumatic stress and depression after childbirth. BJOG Int J Obstet Gynaecol. 2009;116(5):672-680. doi:10.1111/j.14710528.2008.02083.x

15. Rouhe H, Salmela-Aro K, Halmesmäki E, Saisto T. Fear of childbirth according to parity, gestational age and obstetric history. BJOG Int J Obstet Gynaecol. 2009;116(7):1005-1006. doi:10.1111/j.14710528.2009.02154.x
16. Räisänen S, Lehto S, Nielsen H, Gissler M, Kramer M, Heinonen S. Fear of childbirth in nulliparous and multiparous women: a population-based analysis of all singleton births in Finland in 1997-2010. BJOG Int J Obstet Gynaecol. 2014;121(8):965-970. doi:10.1111/1471-0528.12599

17. Lowe NK. Self-efficacy for labor and childbirth fears in nulliparous pregnant women. J Psychosom Obstet Gynecol. 2000;21(4):219-224. doi:10.3109/01674820009085591

18. Tanglakmankhong K, Perrin NA, Lowe NK. Childbirth self-efficacy inventory and childbirth attitudes questionnaire: psychometric properties of Thai language versions. J Adv Nurs. 2011;67(1):193-203. doi:10.1111/j.1365-2648.2010.05479.x

19. Van den Bergh BRH, Mulder EJH, Mennes M, Glover V. Antenatal maternal anxiety and stress and the neurobehavioural development of the fetus and child: links and possible mechanisms. A review. Neurosci Biobehav Rev. 2005;29(2):237-258. doi:10.1016/j. neubiorev.2004.10.007

20. Hu Y, Zhou MF, Wan YP. Study on the current situation and influencing factors of pregnant women's fear of childbirth in late pregnancy. J Nurs Adm. 2020;20(11):768-773.

21. Zheng DD, Zhou LH, Wu XL, Wang LP. Fear of childbirth in primiparas during the late stages of pregnancy and its influencing factors. Matern Child Health Care China. 2018;33(15):3525-3528.

22. Xiao SQ, Liu F, Huang YL, Wang JJ, Li N, Fang YC. Risk factors of fear of childbirth based on decision tree model and logistic regression model. J Nurs. 2020;27(18):1-5. doi:10.16460/j.issn1008-9969.2020.18.001

23. Lowe NI. Self-efficacy for labor and childbirth fears in nuiiiparous pregnant women. J Psychosom Obstet Gynecol. 2000;(December). doi:10.3109/01674820009085591

24. Kish JA. The Development of Maternal Confidence for Labor Among Nulliparous Pregnant Women [Doctoral dissertation]. 2003.

25. Harman P. Fear of Childbirth and related incidence of complications in labor and delivery, In: The 33rd Annual Meeting of the American College Nurse-Midwives; 1988.

26. Wei J, Liu JY, Wu YP. Investigation of fear of childbirth and its influencing factors. J Nurs Sci. 2016;31:86-89.

27. Chen $\mathrm{CH}$, Chen HM, Huang TH. Stressors associated with pregnancy as perceived by pregnant women during three trimesters. Gaoxiong $\mathrm{Yi}$ Xue Ke Xue Za Zhi. 1989;5(9):505-509.

28. Zhang ZJ. Manuals of Behavioral Medicine Measure [In Chinese]. Chinese Medical Electrical Publisher; 2001.

29. Zimet GD, Dahlem NW, Zimet SG, Farley GK. The multidimensional scale of perceived social support. J Pers Assess. 1988;52 (1):30-41. doi:10.1207/s15327752jpa5201_2

30. Huang L, Jiang QJ, Ren WH. Coping style, social support, and psychosomatic symptoms in patients with cancer. Chin Ment Health J. 1996;10:160-161.

31. Cox JL, Holden JM, Sagovsky R. Detection of postnatal depression. Br J Psychiatry. 1987;150(6):782-786. doi:10.1192/bjp.150.6.782

32. Murray D, Cox JL. Screening for depression during pregnancy with the edinburgh depression scale (EDDS). J Reprod Infant Psychol. 1990;8(2):99-107. doi:10.1080/02646839008403615

33. Lee DTS, Yip SK, Chiu HFK, et al. Detecting postnatal depression in Chinese women. Br J Psychiatry. 1998;172(5):433-437. doi:10.1192/ bjp.172.5.433

34. Gao LL, Liu XJ, Fu BL, Xie W. Predictors of childbirth fear among pregnant Chinese women: a cross-sectional questionnaire survey. Midwifery. 2015;31(9):865-870. doi:10.1016/j.midw.2015.05.003

35. Aguilera-Martín Á, Gálvez-Lara M, Blanco-Ruiz M, García-Torres F. Psychological, educational, and alternative interventions for reducing fear of childbirth in pregnant women: a systematic review. $J$ Clin Psychol. 2021;77(3):525-555. doi:10.1002/jclp.23071

36. Moghaddam Hosseini V, Nazarzadeh M, Jahanfar S. Interventions for reducing fear of childbirth: a systematic review and meta-analysis of clinical trials. Women Birth. 2018;31(4):254-262. doi:10.1016/j. wombi.2017.10.007 
37. Akgün M, Boz İ, Özer Z. The effect of psychoeducation on fear of childbirth and birth type: systematic review and meta-analysis. J Psychosom Obstet Gynecol. 2020;41(4):253-265. doi:10.1080/ 0167482X.2019.1689950

38. Liu YJ, Shangguan FF, Zheng RM, Shen YQ, Xu W. Mediating effect of childbirth self-efficacy between pregnant women's mindfulness level and fear of childbirth. Chin J Behav Med Brain Sci. 2019;9:783-787.

39. Saisto T, Ylikorkala O, Halmesmäki E. Factors associated with fear of delivery in second pregnancies. Obstet Gynecol. 1999;94(5 Pt 1):679-682. doi:10.1016/s0029-7844(99)00413-5

40. Collins NL, Dunkel-Schetter C, Lobel M, Scrimshaw SC. Social support in pregnancy: psychosocial correlates of birth outcomes and postpartum depression. J Pers Soc Psychol. 1993;65(6):1243-1258. doi:10.1037//0022-3514.65.6.1243

41. Turner RJ, Grindstaff CF, Phillips N, Social support and outcome in teenage pregnancy. $J$ Health Soc Behav. 1990;31(1):43-57. doi: $10.2307 / 2137044$

42. Wei Q, Zhang SY. Research progress on the psychological states of pregnant women. J Nurs. 2009;16(18):25-27.

43. Lu H, Zhen XX. Social support and postpartum depression among primiparas. Chin J Nurs. 2001;36(10):731-733.

44. Størksen HT, Garthus-Niegel S, Adams SS, Vangen S, EberhardGran M. Fear of childbirth and elective caesarean section: a Population-Based Study. BMC Pregnancy Childbirth. 2015;15 (1):221. doi:10.1186/s12884-015-0655-4

45. Eberhard-Gran M, Slinning K, Eskild A. Fear during labor: the impact of sexual abuse in adult life. J Psychosom Obstet Gynaecol. 2008;29(4):258-261. doi:10.1080/01674820802075998
46. Laursen M, Hedegaard M, Johansen C. Fear of childbirth: predictors and temporal changes among nulliparous women in the Danish national birth cohort. BJOG an Int J Obstet Gynaecol. 2008;115 (3):354-360. doi:10.1111/j.1471-0528.2007.01583.x

47. Zhang Y, Zhou YB, Li HT, et al. Secular trends of institutional delivery rate in China from 1996 to 2015. Natl Med J China. 2017;97(17):1337-1342.

48. Li X, Wang F, Zhao J, Liu S, Jia XY. Analysis on the situation of county-level $\mathrm{MCH}$ organs training basic health institutions-based on the system model of training and developing human resources. Chin Prim Health Care. 2018;32(10):20-21,43.

49. Zhang HM, Wu AQ. Research progress on psychosomatic disorders during the perinatal period. In: Foreign Medical Sciences. 2004:25-29.

50. Kristina Hofberg MW. Psychological Challenges in Obstetrics and Gynecology. Pawson JCE, editor. 2007

51. Toohill J, Fenwick J, Gamble J, Creedy DK. Prevalence of childbirth fear in an Australian sample of pregnant women. BMC Pregnancy Childbirth. 2014;14(1):275. doi:10.1186/1471-2393-14-275

52. Jokić-Begić N, Žigić L, Nakić Radoš S. Anxiety and anxiety sensitivity as predictors of fear of childbirth: different patterns for nulliparous and parous women. J Psychosom Obstet Gynecol. 2014;35 (1):22-28. doi:10.3109/0167482X.2013.866647

53. Lukasse M, Schei B, Ryding EL. Prevalence and associated factors of fear of childbirth in six European countries. Sex Reprod Healthc. 2014;5(3):99-106. doi:10.1016/j.srhc.2014.06.007
Psychology Research and Behavior Management

\section{Publish your work in this journal}

Psychology Research and Behavior Management is an international, peer-reviewed, open access journal focusing on the science of psychology and its application in behavior management to develop improved outcomes in the clinical, educational, sports and business arenas. Specific topics covered in the journal include: Neuroscience, memory and decision making; Behavior modification and management; Clinical applications; Business and sports performance management; Social and developmental studies; Animal studies. The manuscript management system is completely online and includes a very quick and fair peer-review system, which is all easy to use. Visit http://www dovepress.com/testimonials.php to read real quotes from published authors. 